\title{
How to Balance Emission Reduction and Economic Growth in China: Evidence from Shandong Province
}

\author{
Wei LIANG ${ }^{a,{ }^{*}}$, Ming YANG ${ }^{b}$ \\ Business School, University of Jinan, Jinan 250002, China \\ asm_liangw@ujn.edu.cn, b839529439@qq.com \\ ${ }^{*}$ Corresponding author
}

Keywords: Computable general equilibrium model, Carbon tax, Emission reduction, Tax refund.

\begin{abstract}
In recent years, the rapid development of China's economy has brought about a large number of fossil energy consumption, resulting in serious environmental pollution. As an important environmental protection tool, carbon tax has been paid more and more attention, and the carbon tax is in line with the general direction of China's green tax system reform. How do different carbon tax rates affect emission reduction and economic growth? Whether tax refund can reduce the negative influence of the carbon tax on economic growth? In this paper, a computable general equilibrium model (CGE) is applied to study different scenarios: combine different carbon tax rates with tax refund. The results show that it is feasible to achieve the goal of reducing the high carbon energy consumption by levying the carbon tax.
\end{abstract}

\section{Introduction}

Over the past few years, China's economic growth has attracted worldwide attention, however, the imbalance of energy supply and demand and the deterioration of environmental quality has become increasingly prominent. How to achieve a win-win solution between economic development and environmental protection. It has become a major realistic problem that China is confronted with. China has massive coal reserves which account for $13.9 \%$ of the world proven reserves [1]. China is the world's largest coal consuming country, the total amount of coal consumption in 2015 reached 43 billion tons of standard coal (more than $50 \%$ of the world). $\mathrm{CO}_{2}$ makes air pollution more and more serious. The experience of the developed countries shows that the carbon tax plays a significant role in the suppression of coal consumption and environmental protection.

There is a lot of research focusing on the carbon tax from different perspectives. Earlier studies, such as Nordhaus [2] explored the relationship between economic growth and environmental quality and proposed reducing $\mathrm{CO}_{2}$ emissions by the carbon tax. He also studied the impact of the carbon tax on emission reduction from $1980\left(0.14 \$\right.$ /ton $\left.\mathrm{CO}_{2}\right)$ to $2100\left(87.15 \$\right.$ ton $\left.\mathrm{CO}_{2}\right)$. This is an earlier study of the carbon tax in the quantitative simulation, after which there is a growing number of scholars showed a strong interest in carbon tax (environmental tax). For example, Barker [3, 4] studied the influence of the carbon tax on the UK's macro economy by using a large-scale energy-environment-economy model. He found GDP growth is likely to increase under the carbon tax by some $0.2 \%$ above base. Barker's conclusion differs from that of the majority of scholars, and most scholars believe that the carbon tax will have a negative influence on GDP [3, 5-9].

As a big country with great amount of energy consumption, what changes will the carbon tax bring to China? Lots of scholars have begun to study it. Zheng et al. [10] are the first group of scholars to establish CGE models to carry out research on emission reduction in china. After that, this field attracts more and more attention. For example, $\mathrm{Xu}$ et al. [11] think coal tax would certainly benefit China, especially in terms of improving energy structure and mitigating carbon emissions. Wang et al. [9] studied short-term impacts of the carbon tax on sectoral competitiveness and they found that the impact of the carbon tax on competitiveness is very small at the rate of 10 yuan/ton $\mathrm{CO}_{2}$.

Previous researchers found that carbon tax (environment tax or resource tax) contributes to $\mathrm{CO}_{2}$ emission reduction. Those researches mainly studied the influences of the carbon tax reform from a 
national perspective [10]. However, from the provincial level, related researches are relatively rare. Furthermore, from the industry level, the influences of the carbon tax have not been well studied. In order to make up for those, we select a single province (Shandong province) as the research object. The reasons for making this choice are as follows: a) The level of economic development and pollution in different provinces of China is very different. The industrial structure of different provinces also has big differences. If we study the whole of China, research conclusions make little sense to most provinces. In order to obtain a more valuable conclusion, we choose a single province as the research object. b) Shandong province is very representative. Shandong's GDP ranked third in China in 2015 (Six trillion and three hundred billion RMB). By 2014, the total population of Shandong province reached 97 million 890 thousand. Due to the extensive economic development in recent years, the problem of environmental pollution in Shandong province has become more and more serious. It is urgent to find a balance between economic development and environmental protection. Shandong attaches great importance to environmental protection work, has issued a number of documents on environmental protection, such as Work Plan for the Development of Ecological Alert Line in Shandong Province, Guiding Opinions on the Construction of Grid Environment Supervision System in Shandong Province, etc.

\section{Simulation Models}

Compared with other methods, the CGE model possesses its unique merit in energy policy simulations by providing a comprehensive analysis under the general equilibrium framework [8]. Therefore, the CGE model has been extensively used.

The main modules of the model are production module, trade module, income distribution and demand module, environment module, market equilibrium module, macro variable module and macro closure module. The General Algebraic Modeling System (GAMS) is utilized to solve the nonlinear equations. This paper only introduces the main modules.

\section{Production Module}

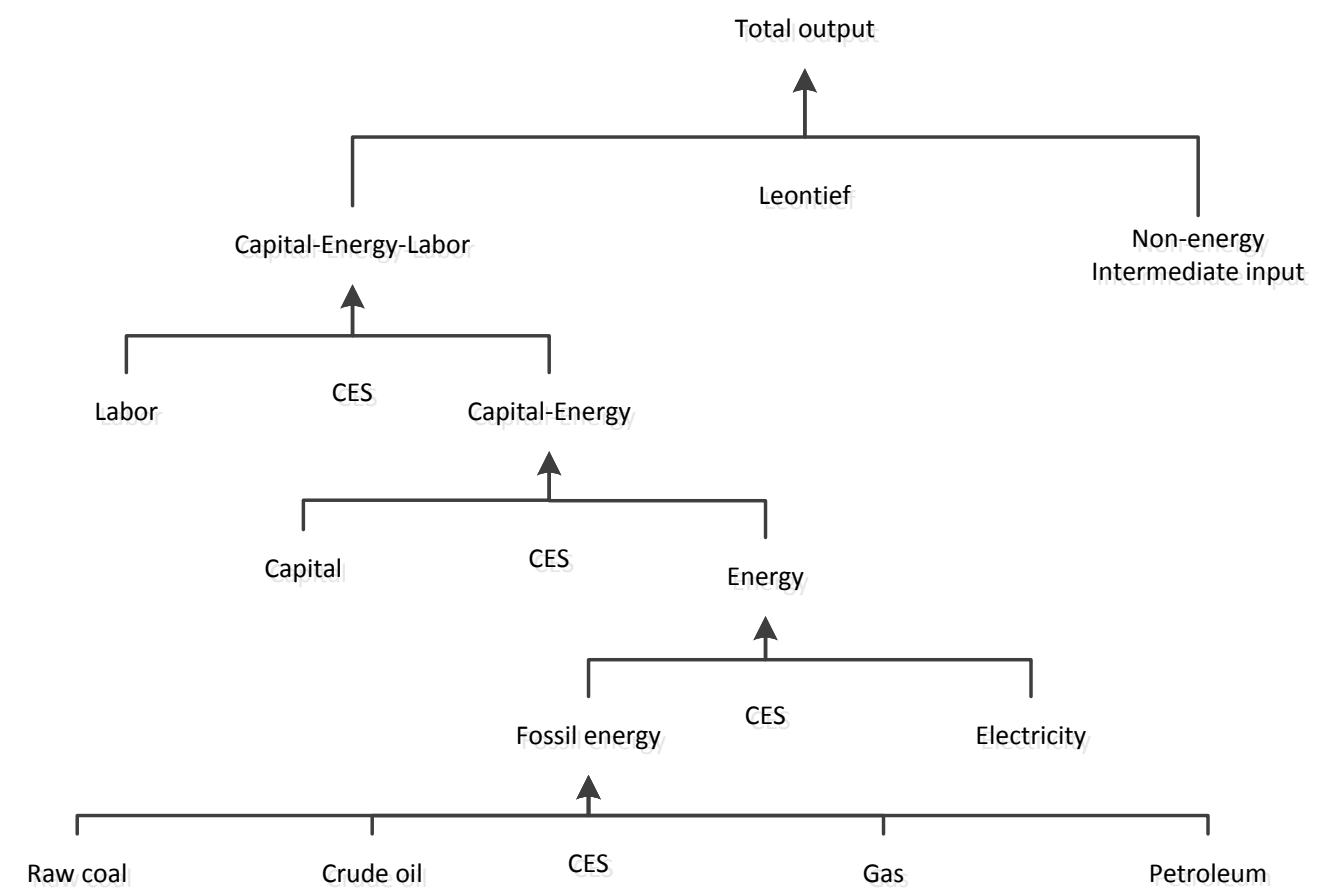

Fig. 1. The model's production structure 
Fig. 1 provides the production structure of the model. Each sector's production process is divided into six levels and most of which are nested in Constant Elasticity of Substitution (CES) functional form, except the topmost level. At the topmost level, the Non-energy Intermediate inputs and Capital-Energy-Labor are nested as Leontief function. We suppose that there is no substitution between Non-energy Intermediate inputs and Capital-Energy-Labor.

\section{Trade Module}

As shown in Fig. 2, the trade structure at the provincial level is different from the national level. We adopt the Armington assumption and assume that there is incomplete substitution between "Import" and commodities "transferred from other provinces", as well as between "total import" and "demand within the province". We assume that "total import" are CES aggregates of "import" and "transferred from other provinces", and "total sales within the province" are CES aggregates of "total import" and "sales within the province".

We presume the "total output within the province" can supply "sales within the province" and "export and transferred to other provinces" simultaneously. The "total output within the province" is CET disaggregates of "sales within the province" and "export and transferred to other provinces". Likewise, the "export and transferred to other provinces" is CET disaggregates of "transferred to other provinces" and "export”.

Some commodities are used as intermediate inputs in the final output. Some commodities are consumed by the inhabitants, the local government and the central government. The rest of the commodities are used for investment, etc.

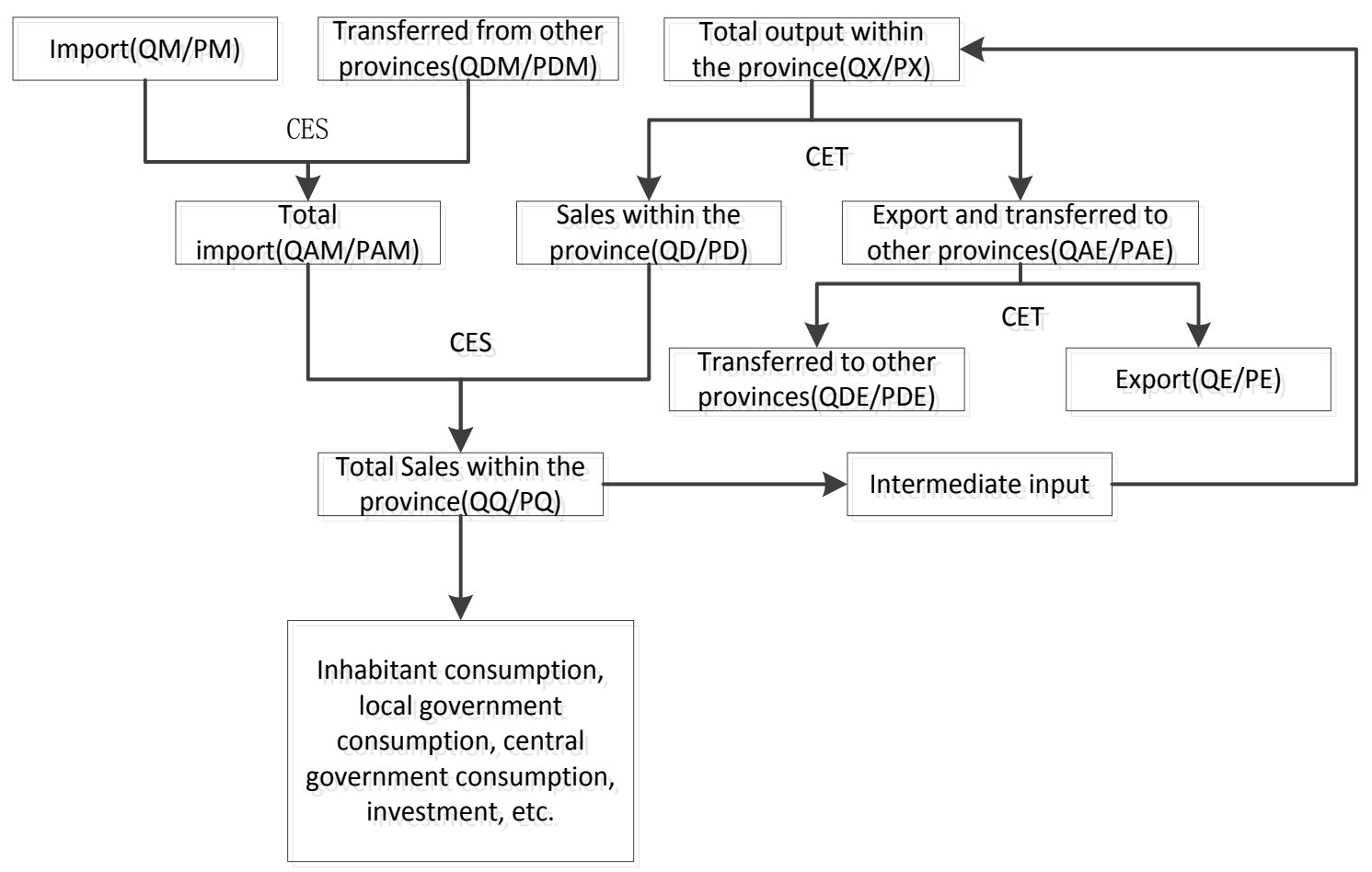

Fig. 2. Trade module structure of the provincial level

\section{Simulation Scenarios}

In scenario 1, there is no tax refund and we aim to research the influence of different carbon tax rates on emission reduction and the macro economy. On the contrary, scenario 2 studies the influence of the tax refund on emission reduction and macro economy and if the tax refund is able to make up the adverse effect of the carbon tax on macro economy to some extent. Scenario 1 and 2 are shown in Table1. 
Table 1. Summary of simulation scenarios.

\begin{tabular}{|l|l|l|l|}
\hline \multicolumn{2}{|l|}{ Scenarios } & Carbon Tax Rate & Tax Refund or Not \\
\hline & S1-1 & 20 yuan/ton $\mathrm{CO}_{2}$ & No tax refund \\
\hline Scenario 1 (S1) & S1-2 & 40 yuan/ton $\mathrm{CO}_{2}$ & No tax refund \\
\hline & S1-3 & 60 yuan/ton $\mathrm{CO}_{2}$ & No tax refund \\
\hline & S2-1 & 20 yuan/ton $\mathrm{CO}_{2}$ & Tax refund \\
\hline Scenario 2 (S2) & S2-2 & 40 yuan/ton $\mathrm{CO}_{2}$ & Tax refund \\
\hline & S2-3 & 60 yuan/ton $\mathrm{CO}_{2}$ & Tax refund \\
\hline
\end{tabular}

Notes: Tax refund means reducing enterprise income tax and inhabitant income tax, the amount of tax reduction is equal to the amount of the carbon tax paid by enterprises and inhabitants.

\section{Simulation Results and Discussion}

Part of simulation results is reported in Table 2.

Table 2. The influences of different carbon tax rates on macroeconomic variables and CO2 emission reduction (\%).

\begin{tabular}{|l|l|l|l|l|l|l|l|}
\hline & & $\mathrm{S} 1-1$ & $\mathrm{~S} 1-2$ & $\mathrm{~S} 1-3$ & $\mathrm{~S} 2-1$ & $\mathrm{~S} 2-2$ & $\mathrm{~S} 2-3$ \\
\hline $\begin{array}{l}\text { The impacts on } \\
\text { emission reduction }\end{array}$ & $\mathrm{CO}_{2}$ & -3.57 & -6.22 & -7.81 & -2.91 & -5.19 & -6.49 \\
\hline \multirow{2}{*}{$\begin{array}{l}\text { The impacts on } \\
\text { macro economy }\end{array}$} & GDP & -0.57 & -0.96 & -1.41 & -0.39 & -0.65 & -0.93 \\
\cline { 2 - 8 } & $\begin{array}{l}\text { Total output within } \\
\text { province }\end{array}$ & -1.34 & -1.72 & -2.12 & -1.13 & -1.55 & -1.87 \\
\cline { 2 - 8 } & $\begin{array}{l}\text { Total consumption } \\
\text { within province }\end{array}$ & -1.49 & -1.91 & -2.37 & -1.23 & -2.08 & -2.17 \\
\cline { 2 - 8 } & Import & 0.83 & 2.06 & 3.12 & 0.40 & 1.58 & 2.63 \\
\cline { 2 - 8 } & $\begin{array}{l}\text { Transferred from } \\
\text { other provinces }\end{array}$ & 4.02 & 5.67 & 6.29 & 1.64 & 2.09 & 3.97 \\
\cline { 2 - 8 } & Export & -0.97 & -1.78 & -2.53 & -0.44 & -0.94 & -1.52 \\
\cline { 2 - 8 } & $\begin{array}{l}\text { Transferred to other } \\
\text { provinces }\end{array}$ & -1.94 & -2.65 & -3.98 & -0.75 & -1.21 & -2.14 \\
\hline
\end{tabular}

\section{Impacts on Emission Reduction}

With the increase of the carbon tax rate, the effect of emission reduction is also getting better and better. Under S1 and S2, the emission reduction effects are different. S2's emission reduction effects are weakened than Scenarios S1. Compared to S2-1, S2-2 and S2-3, S1-1, S1-2 and S1-3 have better performance correspondingly. In a word, tax refund resulting in a worse effects of emission reduction.

Why has this happened? The carbon tax refund will reduce the cost of production and the prices of commodities will drop. Eventually, drop prices will stimulate the increase in the consumption of inhabitant. More inhabitant consumption will pull more intermediate input (energy input and non-energy input). Eventually, under S2 (S2-1, S2-2 and S2-3), the carbon tax refund will bring more CO2 emissions than S1 (S1-1, S1-2 and S1-3).

\section{Impacts on Macroeconomic Variables}

\section{GDP}

With the increase of the tax rate, the GDP is adversely affected. Under S1-1, S1-2 and S1-3, the GDP loss of three tax level are $-0.57 \%,-0.96 \%$ and $-1.41 \%$, correspondingly, under S2-1, S2-2 and S2-3,the adverse influences of the carbon tax of the three levels on GDP are $-0.39 \%,-0.65 \%$ and $-0.93 \%$. Although the negative impacts under S2 (S2-1, S2-2 and S2-3) are less than S1 (S1-1, S1-2 
and S1-3). No matter under S1 (S1-1, S1-2 and S1-3) or S2 (S2-1, S2-2 and S2-3), the adverse influences of the carbon tax on GDP are serious.

The results indicate that the carbon tax has a remarkable negative influence on GDP. But tax refund can offset some negative impacts by stimulating consumption and production. Despite the fact that it cannot completely offset the negative effects, it is very necessary for local government to take appropriate tax refund when levying the carbon tax.

\section{Trade}

Because the research objective of this paper is the provincial administrative region, so when we study the "import", the commodities "transferred from other provinces" should also be studied. For the same reason, the commodities "transferred to other provinces" should be studied when we study the "export”.

The simulation results indicate that the carbon tax leads to the increase of "import" and commodities "transferred from other provinces". Because the carbon tax is only for commodities produced in Shandong not for import and the commodities "transferred from other provinces", so the prices of commodities produced in Shandong rise and their competitiveness decrease. Under the effect of the carbon tax, the substitution effect of imported commodities and transferred commodities from other provinces for commodities within Shandong increase. The carbon tax resulting in a reduction of total outputs, which lead to a decrease of commodities supplies. In order to meet the needs of Shandong province, Shandong need to import more commodities and transfer more commodities from other provinces. In S1-1, S1-2 and S1-3, increases of import are $0.83 \%, 2.06 \%$ and $3.12 \%$. In S2-1, S2-2 and S2-3, increases of import are $0.40 \%, 1.58 \%$ and $2.63 \%$. It is clear that tax refund can stimulate the output to a certain extent, which reduces demand for imported commodities.

In the 6 scenarios, increases of commodities "transferred from other provinces" are $4.02 \%, 5.67 \%$, $6.29 \%, 1.64 \%, 2.09 \%$ and $3.97 \%$. The growth rate of commodities "transferred from other provinces" is significantly higher than that of "import". Obviously, commodities "transferred from other provinces" has a stronger substitution effect of total output than import.

As for export and commodities "transferred to other provinces", the impacts of the carbon tax show negative effects on them. When levying the carbon tax, most industries may be adversely affected, which directly lead to a reduction in output. The reduction of output resulting in reduction in export and commodities "transferred to other provinces".

To a certain extent, tax refund offsets the carbon tax's negative effects. In S1-1, S1-2 and S1-3, the decreases of export are $-0.97 \%,-1.78 \%$ and $-2.53 \%$. In scenario of tax refund, the 3 numbers are $-0.44 \%,-0.94 \%$ and $-1.52 \%$. As for commodities "transferred to other provinces", there is the same trend.

\section{Conclusions}

Taking into account the complexity of the real world economic activities, the existence of various research hypotheses, the inaccurate statistical data and the limitations of the model itself, it is almost impossible for the model to accurately depict the real world. Thus, the purpose of this paper is not to accurately predict the influence of the carbon tax. Although this paper cannot provide accurate quantitative results of the impacts of the carbon tax, it can provide the necessary reference for policy makers to understand the path and transmission mechanism of the impact of the carbon tax on the economy and emission reduction.

This study has the following limitations in general, of course, this is also the direction of future improvement. One of the directions of future research would be to further disaggregate electricity into thermal power, hydropower, nuclear power and renewable energy based power generation. This paper only simulated a kind of tax refund. So another direction is to pay attention to different kind of tax refund and combine the tax refund with the current China's value-added tax reform and resource tax reform, which will provide more references for policy-making. 


\section{Acknowledgement}

Work is financially supported by MOE (Ministry of Education in China) Youth Foundation of Humanities and Social Sciences (Grant No. 14YJCZH087 and No. 15YJC790047), Scientific Research Foundation of University of Jinan (Grant No. 14ZD03 and No. X1219).

\section{References}

[1] Wang Z.L.; Zhi Y.B.; Zhang D.H.; Qiu A.J. China's Coal Resources Endowments with the Pattern of International Reserves. China Population, Resources and Environment. 20 (2010) 318-320. (in Chinese)

[2] Nordhaus W.D. Economic Growth and Climate: The Carbon Dioxide Problem. American Economic Review. 67 (1977) 341-346.

[3] Barker T.; Baylis S.; Madsen P. A UK carbon/energy tax: The macroeconomics effects. Energy Policy. 21 (1993) 296-308.

[4] Barker T. Green Taxation and Environmental Sustainability. Economics of Energy \& Environmental Policy. 2 (2013) 151-154.

[5] Groth C.; Schou P. Growth and non-renewable resources: The different roles of capital and resource taxes. Journal of Environmental Economics and Management. 53 (2007) 80-98.

[6] Zhang Z.; Guo J.; Qian D.; Xue Y.; Cai L. Effects and mechanism of influence of China's resource tax reform: A regional perspective. Energy Economics. 36 (2013) 676-685.

[7] Liu Y.; Lu Y. The Economic impact of different carbon tax revenue recycling schemes in China: A model-based scenario analysis. Applied Energy. 141 (2015) 96-105.

[8] Tang L.; Shi J.; Yu L.; Bao Q. Economic and environmental influences of coal resource tax in China: A dynamic computable general equilibrium approach. Resources, Conservation and Recycling. 117 (2017) 34-44.

[9] Wang X.; Li J.F.; Zhang Y.X. An analysis on the short-term sectoral competitiveness impact of carbon tax in China. Energ Policy. 39 (2011) 4144-4152.

[10] Zheng Y.; Fan M. CGE model and policy analysis of China, Social Science Literature Press: Beijing, China, 1999. (in Chinese)

[11] Xu X.; Chen Q.; Che Y. The impact on regional "resource curse” by coal resource tax reform in China-A dynamic CGE appraisal. Resources Policy. 45 (2015) 277-289. 